\title{
Pentaplegia and Facial Bone Fracture: A Survivable Injury
}

\section{Hani Mhaidli ${ }^{1}$ and Rachid K. Haidar ${ }^{2 *}$}

${ }^{1}$ Department of Orthopaedics, Head of Spine Department, Hospital Universitario de Gran Canaria, Las Palmas, Spain

${ }^{2}$ Orthopaedic Surgery, Chief Division of Orthopaedic, Department of Surgery, American University of Beirut, Beirut, Lebanon

\begin{abstract}
Pentaplegia is a spinal cord injury at or above C4 level, resulting in complete loss of motor functions below the injury level and paralysis of respiratory muscles. Facial injuries might be a factor for early identification of these patients and in implying prompt management. Here, we report a patient who was injured in a motor vehicle accident and sustained facial injury and cardiopulmonary symptoms. His imaging studies showed atlanto-axial dissociation and maxillary fracture. He survived the accident but continued to have pentaplegia. Presence of facial fractures might help in suspicion and early identification of such injuries, where prompt management remains essential for survival in complete pentaplegia and for avoiding deterioration in incomplete injuries.
\end{abstract}

Keywords: Atlanto-axial dislocation; Cervical spinal cord injury; Facial fracture; Pentaplegia

\section{Introduction}

Pentaplegia is defined as cervical spinal cord injury (CSI) above C4 level which results in complete paralysis of upper and lower extremities (tetraplegia) in addition to respiratory muscle paralysis. Head and neck movements might be preserved to a very limited degree as per level of facial muscle involvement; however, chest and diaphragmatic muscles are paralyzed and a ventilator is necessary for breathing [1].

Most spinal cord injuries, including cervical, are caused by trauma to the vertebral column, hence affecting the spinal cord. Any fracturedislocation at axis or atlas levels is usually fatal, mostly diagnosed postmortem [2]. Here, we present a case of pentaplegia, which survived, after traumatic atlanto-axial dissociation associated with maxillary fracture, and discuss the correlation between facial fracture and CSI, its early diagnosis and management practices.

\section{Case Study}

A 25 year-old male involved in motor-vehicle-accident was found by rescue team at the site of accident to have evident facial injury in addition to apnea and bradycardia. Immobilization of cervical spine, endotracheal intubation and mechanical ventilation was performed immediately. Then, the patient was transferred to emergency room where X-rays (Figure 1) and CT evaluation (Figure 2) showed complex atlanto-axial injury with C1-C2 dissociation in addition to superior maxillary fracture (Figure 3). There was no brain injury. Neurological exam revealed complete pentaplegia. The patient underwent $\mathrm{C} 1-\mathrm{C} 2$ posterior fixation (Figure 4). Three-year post-surgery, the patient is still alive in a special care unit requiring ventilator.

\section{Discussion}

Traumatic cervical dislocation is usually caused by severe deceleration injury; where strong shearing and rotational forces damages the spinal ligaments. It is usually fatal because of secondary neurologic and vascular insults [1].

Emergency medical service personnel should assume spinal cord injury when faced with any trauma patient. Clinical criteria, usually used as a guide for the need of spinal immobilization, are: altered consciousness, neurologic abnormality, evidence of intoxication, pain or tenderness over the spine area, distracting painful injury, and/or significant trauma [3]. However, even in the absence of above mentioned factors, spine immobilization should be applied until lateral cervical spine $\mathrm{X}$-ray is negative [4].
The American College of Surgeons suggests high risk of CSI with injuries above the clavicle level [5]; others do not agree with this correlation [6]. We reviewed the medical literature using cervical spine injury, face trauma and related terminologies for such correlation studies and found ten relevant studies (Table 1). The CSI incidence associated with facial trauma ranged from $2 \%$ to above $10 \%$. Some studies introduced Glasgow Coma Scores (GCS) in facial trauma patients, which enhanced the correlation between facial trauma and CSI [6]. Two recent studies on millions of trauma patients reported CSI incidence in $6.7 \%$ of facial fractures [7], $4.9-8 \%$ in isolated facial fracture and $7-10.8 \%$ in multiple facial fractures [8].

Since CSI is difficult to identify in the field but other injuries encountered in similar incidents like craniofacial fractures are readily identified [1], assertion of such correlation may contribute to decrease in the percentage of missed diagnoses.

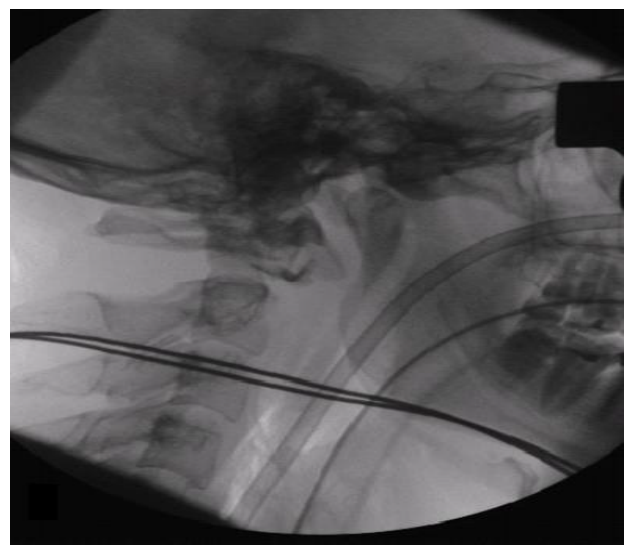

Figure 1: Pre-operative X-ray shows atlanto-axial dissociation.

*Corresponding author: Rachid Haidar, Professor of Clinical Orthopaedic Surgery, Chief Division of Orthopaedic Surgery, Department of Surgery, American University of Beirut Medical Center, P.O. Box 11-0236, Riad El Solh, 1107 2020, Beirut, Lebanon, Tel: +961-3310877; Fax: +961-1363291; E-mail: rh00@aub.edu.lb

Received November 10, 2014; Accepted June 27, 2015; Published June 30, 2015

Citation: Mhaidli H, Haidar RK (2015) Pentaplegia and Facial Bone Fracture: A Survivable Injury. J Spine 4: 231.doi:10.4172/21657939.1000231

Copyright: $\odot 2015$ Mhaidli H, et al. This is an open-access article distributed under the terms of the Creative Commons Attribution License, which permits unrestricted use, distribution, and reproduction in any medium, provided the original author and source are credited. 


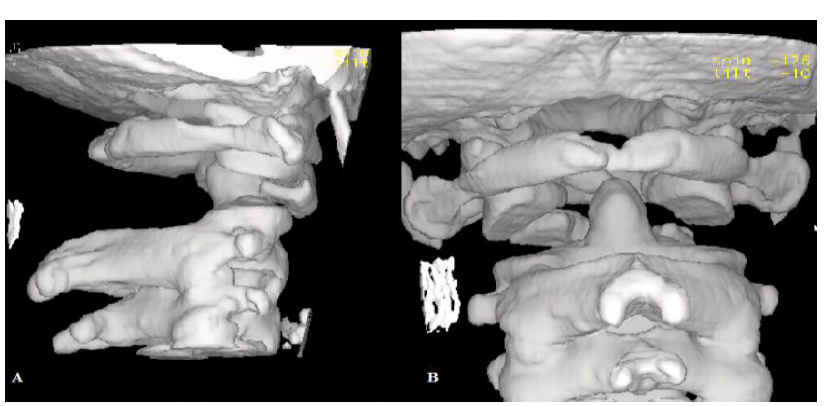

Figure 2: (A) Lateral and (B) Postero-anterior 3D reconstruction CT-scan showing gross $\mathrm{C} 1-\mathrm{C} 2$ dissociation.

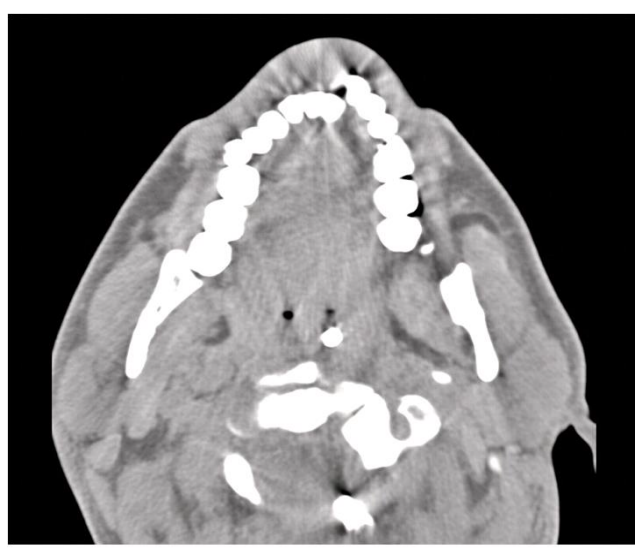

Figure 3: Axial CT-scan showing maxillary fracture.

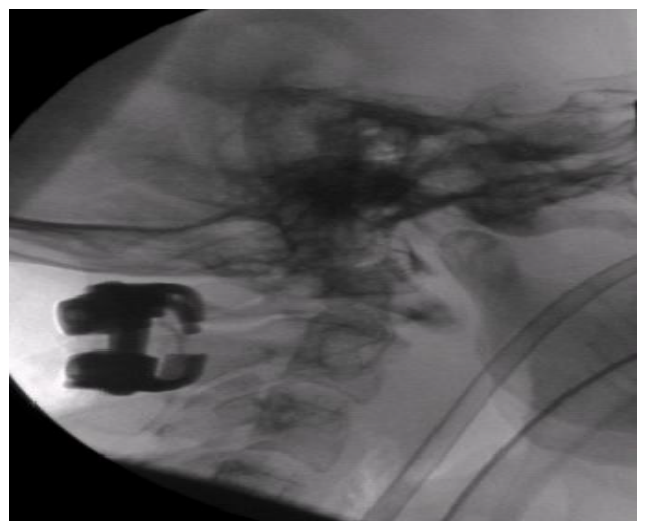

Figure 4: Post-operative lateral view of cervical spine showing dissociationreduction with fixation.

Diagnosis of atlanto-axial dissociation, if present, is usually not clinically obvious and the physician should have high index of suspicion with patients arriving with facial injuries, breathing difficulties, neurological deficits or with symptoms of neurogenic shock such as hypotension and bradycardia. An early diagnosis of atlanto-axial dissociation through radiography and CT-scan imaging will prevent delay in treatment and any further injury.

Preliminary treatment starts on site, by securing $\mathrm{ABCs}$ and immobilizing the patient. Various immobilization techniques exist with no comparative study to identify the optimal approach [9]; nonetheless, stabilization decreases mortality rate and complete spinal cord lesion from $55 \%$ to $39 \%$ [10].
The most prognostic factors to be monitored in such patients are cardiac, hemodynamic, and respiratory parameters. To prevent reduced perfusion to the spinal cord, hypotension should be corrected promptly and mean-arterial-pressure maintained above $85-90 \mathrm{mmHg}$ in the first week which correlates with better long-term neurological outcome [11]. Continuous breathing assessment should be performed because delayed swelling or hematoma formation might obstruct the airway, even if respiratory distress was not present from the beginning.

Also, there are some currently controversial treatment modalities, which aim at early neuroprotection and/or minimizing secondary injury like steroid injection and hypothermia. Clinical studies indicated that methylprednisolone administration within 8 hours post-injury might be able to improve neurological and functional outcomes [12]. Additionally, recent animal studies and patient reports indicated the role of moderate intravascular hypothermia $\left(33^{\circ} \mathrm{C}\right.$ for 48 hours) in improving patient status by at least one ASIA level [13-17].

Displaced spine injuries should be reduced and alignment maintained either by surgery or orthotics. Emergency surgery is not part of the standard early treatment for patients with complete tetraplegic or pentaplegic; however, once patient is stable and medically cleared to undergo surgery, open reduction and internal fixation is in-order. Emergency surgical decompression is required in case of incomplete neurological injury with evidence of neural compression by diagnostic imaging. Recent studies shows less neurological deficit (ASIA D as compared to ASIA C) with early decompression (within 24 hours) for non-traumatic acute central cord injury patients [18]. However, decompression surgery timing and outcome is still a controversial issue in traumatic injuries.

\section{Conclusion}

Complete high CSI are becoming more survivable due to increased awareness among health care personnel on early identification and advancement in management to prevent further injury. An important red flag for upper CSI is respiratory distress, and facial fracture is another hint of CSI. Prompt recognition of such injuries is extremely important because these might be incomplete or survivable cases. Unfortunately, our patient did not recover any of his functions, but he survived a lethal injury.

\begin{tabular}{|c|c|c|}
\hline Reference & Facial injury patients & $\%$ of CSI patients \\
\hline Lewis et al. [19] & 84 facial fractures & $30.95 \%$ had high level CS \\
\hline Haug et al. [20] & $\begin{array}{l}563 \text { patients with facial fractures } \\
\text { (mandibular fracture } 91 \% \text { ) }\end{array}$ & $1.24 \%$ had high level CSI \\
\hline Williams et al. [6] & 676 patients with facial injury & $4.2 \%$ had CSI \\
\hline Hills et al. [21] & $\begin{array}{c}700 \text { facial injury with AIS } \geq 2 \\
(285 \text { facial injury with AIS }=3 \text { or } 4)\end{array}$ & $\begin{array}{c}2 \% \text { had CSI }(2.8 \% \text { had } \\
\text { CSI })\end{array}$ \\
\hline Roccia et al. [5] & $\begin{array}{c}2482 \text { patients with maxillofacial } \\
\text { trauma }\end{array}$ & $\begin{array}{l}0.85 \% \text { had amyelic } \\
\text { cervical spine fractures }\end{array}$ \\
\hline Elahi et al. [22] & $\begin{array}{l}3356 \text { patients with } \\
\text { craniomaxillofacial fractures }\end{array}$ & $\begin{array}{c}3.69 \% \text { had CSI and } \\
\text { increased to } 8.86 \% \text { with } \\
\text { multiple facial fractures }\end{array}$ \\
\hline Mithani et al. [23] & $\begin{array}{l}4786 \text { patients with maxillofacial } \\
\text { fractures }\end{array}$ & $9.63 \%$ had CSI \\
\hline Mulligan et al. [7] & 117417 facial fractures & $\begin{array}{c}6.7 \% \text { had CSI and } \\
\text { increased to } 7.8 \% \text { with } \\
\text { combined facial fracture } \\
\text { and head injury }\end{array}$ \\
\hline Mulligan et al. [8] & 148478 facial fractures & $\begin{array}{l}4.9-8.0 \% \text { had CSI for } \\
\text { different single facial } \\
\text { fractures and } 7.0-10.8 \% \\
\text { had CSI with two or more } \\
\text { facial fractures }\end{array}$ \\
\hline
\end{tabular}

Table 1: Studies correlating cervical spinal injury with facial injuries, were identified in PubMed and EMBASE medical literature databases. 


\section{References}

1. Chen JW (2008) Cervical spine injuries. Oral Maxillofac Surg Clin North Am 20: $381-391$

2. Kleweno CP, Zampini JM, White AP, Kasper EM, McGuire KJ (2008) Survival after concurrent traumatic dislocation of the atlanto-occipital and atlanto-axia joints: a case report and review of the literature. Spine (Phila Pa 1976) 33: E659-662.

3. Domeier RM (1999) Indications for pre-hospital spinal immobilization. PreHospital Emergency Care 3: 251-253.

4. Werman HA, White LJ, Herron H, Deppe S, Love L, et al. (2008) Clinical clearance of spinal immobilization in the air medical environment: a feasibility study. J Trauma 64: 1539-1542.

5. Roccia F, Cassarino E, Boccaletti R, Stura G (2007) Cervical spine fractures associated with maxillofacial trauma: an 11-year review. J Craniofac Surg 18: 1259-1263.

6. Williams J, Jehle D, Cottington E, Shufflebarger C (1992) Head, facial, and clavicular trauma as a predictor of cervical-spine injury. Ann Emerg Med 21: 719-722.

7. Mulligan RP, Friedman JA, Mahabir RC (2010) A nationwide review of the associations among cervical spine injuries, head injuries, and facial fractures. J Trauma 68: 587-592.

8. Mulligan RP, Mahabir RC (2010) The prevalence of cervical spine injury, head injury, or both with isolated and multiple craniomaxillofacial fractures. Plast Reconstr Surg 126: 1647-1651.

9. Pimentel L, Diegelmann L (2010) Evaluation and Management of Acute Cervical Spine Trauma. Emerg Med Clin N Am 28: 719-738.

10. Garfin SR, Shackford SR, Marshall LF, Drummond JC (1989) Care of the multiply injured patient with cervical spine injury. Clin Orthop Relat Res 239: 19-29.

11. Vale FL, Burns J, Jackson AB, Hadley MN (1997) Combined medical and surgical treatment after acute spinal cord injury: Results of a prospective pilot study to assess the merits of aggressive medical resuscitation and blood pressure management. J Neurosurg 87: 239-246.

12. Bracken MB (2002) Steroids for acute spinal cord injury. Cochrane Database Syst Rev 3: CD001046.
13. Dietrich WD, Atkins CM, Bramlett HM (2009) Protection in animal models of brain and spinal cord injury with mild to moderate hypothermia. J Neurotrauma 26: $301-312$.

14. Yu CG, Jimenez O, Marcillo AE, Weider B, Bangerter $\mathrm{K}$, et al. (2000) Beneficial effects of modest systemic hypothermia on locomotor function and histopathology damage following contusion-induced spinal cord injury in rats. J Neurosurg 93: 85-93.

15. Cappuccino A, Bisson LJ, Carpenter B, MarzoJ, Dietrich WD, et al. (2010) The use of systemic hypothermia for the treatment of an acute cervical spinal cord injury in a professional football player. Spine (Phila Pa 1976) 35: E57-62.

16. Levi AD, Green BA, Wang MY, Dietrich WD, Brindle T, et al. (2009) Clinical application of modest hypothermia after spinal cord injury. J Neurotrauma 26: 407-415.

17. Levi AD, Casella G, Green BA, Dietrich WD, Vanni S, et al. (2010) Clinical outcomes using modest intravascular hypothermia after acute cervical spinal cord injury. Neurosurgery 66: 670-677.

18. Lenehan B, Fisher CG, Vaccaro A, Fehlings M, Aarabi B, et al. (2010) The urgency of surgical decompression in acute central cord injuries with spondylosis and without instability. Spine (Phila Pa 1976) 35: 180-186.

19. Lewis VL Jr, Manson PN, Morgan RF, Cerullo LJ, Meyer PR Jr (1985) Facial injuries associated with cervical fractures: recognition, patterns, and management. J Trauma 25: 90-93.

20. Haug RH, Wible RT, Likavec MJ, Conforti PJ (1991) Cervical spine fractures and maxillofacial trauma. J Oral Maxillofac Surg 49: 725-729.

21. Hills MW, Deane SA (1993) Head injury and facial injury: is there an increased risk of cervical spine injury? J Trauma 34: 549-553.

22. Elahi MM, Brar MS, Ahmed N, Howley DB, Nishtar S, et al. (2008) Cervica spine injury in association with craniomaxillofacial fractures. Plast Reconstr Surg 121: 201-208.

23. Mithani SK, Hilaire HS, Brooke BS, Smith IM, Bluebond-Langner R, et al. (2009) Predictable patterns of intracranial and cervical spine injury in craniomaxillofacial trauma: analysis of 4786 patients. Plast Reconstr Surg 123 1293-1301. 